\title{
Effect of Titanium Additions upon Microstructure and Properties of Precipitation-Strengthened Fe-Ni-Al-Cr Ferritic Alloys
}

\author{
Michael J. S. Rawlings ${ }^{\mathrm{a}, * *}$, Christian H. Liebscher ${ }^{\mathrm{b},{ }^{*}}$, Mark Asta ${ }^{\mathrm{b}, \mathrm{c}}$, David C. Dunand ${ }^{\mathrm{a}}$ \\ ${ }^{\mathrm{a}}$ Department of Materials Science \& Engineering, Northwestern University, Evanston, IL 60208, USA \\ ${ }^{\mathrm{b}}$ Department of Materials Science \& Engineering, University of California, Berkeley, CA 94720, USA \\ ${ }^{\mathrm{c}}$ Materials Sciences Division, Lawrence Berkeley National Laboratory, Berkeley, CA 94720, USA \\ * currently at: Max-Planck-Institut für Eisenforschung GmbH, Düsseldorf, Germany \\ ** corresponding author: michaelrawlings2015@u.northwestern.edu
}

\begin{abstract}
$\underline{\text { Abstract }}$
Various amounts of $\mathrm{Ti}(0,2,4$ and $6 \mathrm{wt} \%)$ is added to a ferritic alloy with a nominal composition of $\mathrm{Fe}-10 \mathrm{Cr}-10 \mathrm{Ni}-6.5 \mathrm{Al}-3.4 \mathrm{Mo}-0.25 \mathrm{Zr}-0.005 \mathrm{~B}$ (wt.\%) (FBB8). The microstructure and composition of the matrix and precipitate phases are characterized by scanning electron microscopy (SEM) and transmission electron microscopy (TEM). For the Ti-modified steels, the bcc ferritic matrix is strengthened by submicron $\mathrm{L}_{1}-\mathrm{Ni}_{2} \mathrm{TiAl}$ type precipitates which contain (i) Fe-inclusions with the precipitates' overall diameters ranging from 100-500 $\mathrm{nm}$ for both FBB8-4 wt.\% Ti and FBB8-6 wt.\%Ti, or (ii) B2-NiAl sub-precipitates with an average diameter of 50 to $100 \mathrm{~nm}$ for FBB8-2 wt.\%Ti. By contrast, the Ti-free FBB8 alloy contains B2-NiAl precipitates with Fe-inclusions. The four FBB8-Ti alloys were subjected to creep experiments at $700^{\circ} \mathrm{C}$ in the stress range of 60-300 MPa. Threshold stresses for all studied compositions were observed, ranging from 69 to $179 \mathrm{MPa}$, with the most creep-resistant alloy being FBB8-2Ti with L2 1 /B2 precipitates. Based on these mechanical results and detailed electron microscopy observations, the creep mechanism is rationalized to be general dislocation climb with repulsive elastic interaction between coherent precipitates and the matrix dislocations.
\end{abstract}

\section{Introduction}

Ferritic steels, due to their excellent thermal conductivity, low thermal expansion coefficient and low cost, are attractive replacements for austenitic steels and Ni-based superalloys for high-temperature, high-stress applications, such as turbine blades in thermal power plants [1-3]. However, their practical usage in such applications is limited because of their insufficient creep resistance at temperatures above $600^{\circ} \mathrm{C}$ [4]. Previous studies of ferritic Fe-Ni-Al-Cr-Mo steels, with approximate compositions of $\mathrm{Fe}$ (bal.), 9$11 \mathrm{Ni}, 9-12 \mathrm{Cr}, 3-10 \mathrm{Al}, 3-3.5 \mathrm{Mo}, 0.005 \mathrm{~B}$ (nominal wt.\%) [5-7], have demonstrated the ability to precipitation-strengthen a body-centered cubic (bcc) $\alpha$-Fe-Cr-Ni-Al-Mo matrix with B2-ordered NiAl precipitates (designated as $\beta^{\prime}$ ) [8] with sub-micron size. Due to a low lattice parameter mismatch between the $\beta$ ' precipitates and the $\alpha$-ferritic matrix 
(0.2887 and $0.2866 \mathrm{~nm}$, respectively [9]), a coherent $\alpha / \beta$ ' structure can be obtained, providing a bcc analog to the face-centered cubic (fcc) $\gamma / \gamma^{\prime}$ structure found in Ni-based superalloys $[10,11]$. The coherent, two-phase $\alpha / \beta$ ' microstructure, in the Fe-Ni-Cr-Al(Mo) steels studied [7], is responsible for their excellent coarsening and creep properties above $600^{\circ} \mathrm{C}$.

In B2-NiAl, replacing half the $\mathrm{Al}$ atoms by Ti results in the Heusler-phase (L2 $\left.{ }_{1}\right)$ $\mathrm{Ni}_{2} \mathrm{TiAl}$, which displays greater creep resistance than $\mathrm{NiAl}$ when tested in their respective monolithic forms $[12,13]$. The lattice parameter mismatch between the $\mathrm{L}_{1}\left(\mathrm{Ni}_{2} \mathrm{TiAl}-\right.$ type) phase and Fe-based matrix (0.5865 and $0.2866 \mathrm{~nm}$, respectively [14]) is sufficiently low as to allow for a semi-coherent Heusler-phase precipitate structure within the (bcc) ferritic matrix in ferritic steel containing $\mathrm{Ni}, \mathrm{Al}$ and $\mathrm{Ti}$. Recent microstructure studies in such Ti-modified steels have shown dispersion of both B2 (NiAl-type) and L2 ${ }_{1}\left(\mathrm{Ni}_{2} \mathrm{TiAl}^{-}\right.$ type) phases in a Fe-based matrix where the $\mathrm{B} 2$ domains have formed only within the $\mathrm{L} 2_{1}$ precipitates, giving rise to a hierarchical microstructure of finer precipitates within larger precipitates $[15,16]$.

In this paper, we present a systematic microstructural and creep study of alloys based on the well-studied FBB8 composition (Fe-10Cr-10Ni-6.5Al-3.4Mo-0.25Zr$0.005 \mathrm{~B}$ wt.\%) [17-21], to which 2, 4 or $6 \mathrm{wt} . \% \mathrm{Ti}$ is added, with the aim of modifying the B2-NiAl precipitate phase found in the FBB8 alloy to the more creep resistant L21Ni2TiAl phase. The grain and precipitate microstructure of each alloy, in both the asheat-treated and crept states, is analyzed by scanning- and transmission electron microscopy (SEM and TEM). The mechanical properties of the alloys are discussed in terms of their microstructures. The most creep-resistant alloy with 2 wt.\% Ti shows a hierarchical precipitate microstructure of $\mathrm{L} 2_{1}$ precipitates containing fine plate-like NiAl sub-precipitates; by contrast, the less creep-resistant alloys with 0,4 and 6 wt.\% Ti, display a single type of precipitate: $\mathrm{NiAl}$ for $0 \% \mathrm{Ti}$ and $\mathrm{L} 2{ }_{1}$ containing fine $\alpha$-Fe rich plates for 4 and $6 \% \mathrm{Ti}$.

\section{Experimental Procedures}

Three alloy ingots were prepared by arc-melting using commercially-pure metals (99.7\% in purity), and then drop cast into a copper mold by Sophisticated Alloys (Butler, PA). Their chemical compositions were measured by direct-current plasma mass spectroscopy at ATI Wah Chang (Albany, OR). As shown in Table 1, the compositions, for the original Ti-free FBB8, and the FBB8 alloys modified with 2 and 6 wt. \% Ti (labeled in what follows as FBB8-2Ti and $-6 \mathrm{Ti}$, respectively) are close to the nominal compositions. A fourth alloy with 4 wt.\% Ti (labelled FBB8-4Ti) was created by arc melting equal amounts of FBB8-2Ti and FBB8-6Ti and solidified on a copper heath. The cast ingots were homogenized at $1200{ }^{\circ} \mathrm{C}$ for $0.5 \mathrm{~h}$ in evacuated quartz tubes, air-cooled, aged at $700{ }^{\circ} \mathrm{C}$ for $100 \mathrm{~h}$ in air, and air-cooled on a ceramic block. Once heat-treated, compression creep specimens were fabricated out of the ingots by electro-discharge 
machining (EDM). The compression specimens had dimensions of 8x8x16 mm or 10x10x20 mm.

SEM samples with dimensions of $\sim 8 \times 8 \times 3 \mathrm{~mm}$ were cut from crept alloys using a Struers Accutom-5 high speed saw, mounted in high-temperature epoxy using a Struers LaboPress-1 hot mounting press and polished to a $1 \mu \mathrm{m}$ finish with a suspended diamond polishing solution. Back-scattered micrographs and phase compositions of the unetched samples were taken using a Hitachi S3400 (EPIC) SEM microscope with an Oxford instruments AZtec EDS detector operated at $15 \mathrm{kV}$. Images were analyzed using the software Image $\mathrm{J}$ to determine sizes of the grains and precipitates present in the alloys.

TEM samples with a $3 \mathrm{~mm}$ diameter were cut using a rotary disc cutter. The discs were ground to $80-100 \mu \mathrm{m}$ in thickness and further thinned to electron transparency using an electrolyte of $20 \%$ perchloric acid at a temperature of $-30^{\circ} \mathrm{C}$. Superlattice dark-field and scanning TEM (STEM) imaging was performed in a Libra200MC (Zeiss) and Tecnai F20 (FEI) microscopes operated at $200 \mathrm{kV}$ and a Titan 80-300 (FEI) microscope operated at $300 \mathrm{kV}$.

Constant load compression creep experiments were conducted at $700{ }^{\circ} \mathrm{C}$ on the polycrystalline specimens, with grain sizes ranging from 0.2 to $2 \mathrm{~mm}$. The samples were placed between two boron-nitride-lubricated silicon carbide platens and heated under negligible stress in a three-zone furnace with the temperature controlled, within $1^{\circ} \mathrm{C}$, by a thermocouple placed within $10 \mathrm{~mm}$ of the sample. The load-train displacement was measured with a linear variable displacement transducer (LVDT) with a resolution of $10 \mu \mathrm{m}$ and corresponded to the sample deformation once temperature was stabilized. The applied load was held constant until a well-defined minimum secondary strain rate was observed (i.e., when the total strain accumulated was at least two to three times the error of the test) and then the load was increased. This procedure was repeated up to the point where the cumulative creep strain reached $10 \%$, a limit chosen to prevent sample barreling. At this point, the samples were air-cooled at a rate of $\sim 50^{\circ} \mathrm{C} / \mathrm{min}$ while under the terminal stress.

\section{Results and Discussion}

\subsection{SEM Investigation of Crept Microstructure}

The micron-scale microstructural features of the three Ti-containing modified FBB8 alloys, as well as the original Ti-free FBB8 alloys, are investigated by scanning electron microscopy (SEM).

Fig 1a shows microstructure observed by SEM in a specimen of FBB8-0Ti that was aged at $700^{\circ} \mathrm{C}$ for $100 \mathrm{~h}$ and crept to a strain of $10 \%$ over a range of stresses at $700^{\circ} \mathrm{C}$ for $190 \mathrm{~h}$. This alloy displays grains that vary in size from 150-300 $\mu \mathrm{m}$. Fig 1a shows the presence of a high Z-contrast, flake-like precipitate phase that is uniformly 
distributed throughout the matrix grains, with a typical planar width of about 1-3 $\mu \mathrm{m}$ and a submicron thickness. A similar phase can be seen, in Fig. 1b, decorating the grain boundary with a discrete blocky morphology and a sub-micron average size. EDS analysis performed on these precipitates shows that they are highly enriched in $\mathrm{Zr}$ and $\mathrm{Fe}$ (and to a less extent in Mo) but in no other element present in the alloy consistent with the $\mathrm{Fe}_{23} \mathrm{Zr}_{6}$-type intermetallic phase, previously found as precipitate in this alloy [21]. The size of these precipitates is well below the size of the x-ray interaction volume, so exact composition or stoichiometry cannot be ascertained. As boron cannot be detected by EDS, it cannot be excluded that these precipitates are $\mathrm{Zr}$ - and Fe-rich borides; this is however very unlikely, given the low amount of B in the alloy. Both types of Zr-rich precipitates are shown at higher magnification in Fig. $1 \mathrm{~b}$ precipitated within grains and on a grain-boundary. A precipitate depletion zone with a width of $\sim 2-3 \mu \mathrm{m}$ is visible on either side of the grain boundaries, where the matrix is free of $\mathrm{Zr}$-rich precipitates. Fig 1c shows clusters of Zr-rich matrix precipitates at a higher magnification. Fig $1 \mathrm{~d}$ reveals the presence of a submicron precipitate phase that is evenly distributed throughout the matrix and has a darker $\mathrm{Z}$ contrast indicative of lower- $\mathrm{Z}$ elements (unlike the bright contrast of the high-Z, Zr-rich precipitates). These submicron, intragranular precipitates were previously identified as B2-NiAl with Fe-inclusions [18,21,22]. Their average radii of $57 \pm 9 \mathrm{~nm}$ is in agreement with the previously reported value of $62-65 \mathrm{~nm}$ for the same alloy composition exposed to the same heat treatment times and temperatures used here $[21,23,24]$.

Fig 2a shows the FBB8-2Ti alloy, with millimeter-size grains, which was aged at $700^{\circ} \mathrm{C}$ for $100 \mathrm{~h}$ and then subjected to creep for $410 \mathrm{~h}$ at $700{ }^{\circ} \mathrm{C}$ while accumulating $4 \%$ stain. Zr-rich precipitates, with similar bright Z-contrast to the micron-size Zr-rich phases found in FBB8-0Ti alloys and with a mix of flake-like and spherical morphologies, are uniformly dispersed throughout the matrix, with an average size of $\sim 5 \mu \mathrm{m}$ (and a few instances of $40 \mu \mathrm{m}$ sizes). The grain boundaries are mostly decorated with these Zr-rich precipitates that have an elongated shape and long sizes of $2-5 \mu \mathrm{m}$. Both the intragranular precipitates and the precipitates at the grain boundary are shown at higher magnification in Fig. 2b, which also illustrates a depletion zone of 30-40 $\mu$ m width on either side of the grain boundaries in which no $\mathrm{Zr}$-rich precipitates are visible. Fig 2c, taken at much higher magnification, shows the discrete nature of the $\mathrm{Zr}$-rich precipitates along grain boundaries, in addition to low Z-contrast, sub-micron precipitates uniformly dispersed within the grains, which are identified as $\mathrm{L}_{2}-\mathrm{Ni}_{2} \mathrm{TiAl}$, based on TEM results discussed in Section 3.2. Finally, Fig 2d reveals a special case in this alloy where two distinct phases nucleated at the grain boundary with a brighter Z-contrasted phase (1) surrounding a dense, slightly darker-contrasted phase (2). Phase (1), which is the closest Z-brightness to the phase most readily seen throughout the alloy, has an EDS measured composition which is almost identical to that measured in the FBB8-0Ti alloy (strong enrichment in $\mathrm{Zr}$ only); phase (2) is enriched in $\mathrm{Zr}$, Ti and Mo, as compared to the matrix, 
pointing to a different intermetallic phase (again, rather than a boride, given the very low B content). This micrograph also displays a sub-grain boundary (S) continuously decorated with $\mathrm{L} 2_{1}-\mathrm{Ni}_{2} \mathrm{TiAl}$-type precipitates, which is associated with a narrow precipitate-free zone, with a width of 0.5-1 $\mu \mathrm{m}$ (3). Intragranular submicron $\mathrm{L}_{1}-\mathrm{Ni}_{2} \mathrm{TiAl}$ type precipitates (darker contrast) are seen within the grains and are discussed in greater detail, based on TEM observations, in Section 3.2.

Fig 3a shows the microstructure observed by SEM in a specimen of FBB8-4Ti that was aged at $700^{\circ} \mathrm{C}$ for $100 \mathrm{~h}$ and crept to a strain of $8 \%$ over a range of stresses at $700^{\circ} \mathrm{C}$ for $215 \mathrm{~h}$. The alloy exhibits a grain size of 50-200 $\mu \mathrm{m}$, which is significantly smaller than that of its FBB8-2Ti and FBB8-6Ti counterparts but on par with the FBB8OTi sample, as evident in Fig 1a. Dark precipitates are visible in Fig 3a and are identified as surface oxide inclusions (pits) that were not fully polished from the surface of the sample during metallographic preparation and are thus not representative of the bulk structure. In addition, Fig $3 \mathrm{~b}$ at higher magnification displays a dense network of $\mathrm{Zr}$-rich precipitates along the grain boundaries as well as a dense dispersion of Zr-rich precipitates within the grains. These intragranular high-Zr precipitates are very fine, compared to those found in the other studied alloys, with sizes below $1 \mu \mathrm{m}$ (as shown in Fig 3c) and a narrow precipitation-free zone ( $2 \mu \mathrm{m}$ in width), on both sides of the grain boundaries, in which no Zr-rich precipitates are formed. The intragranular high- $\mathrm{Zr}$ precipitates have sizes similar to those found at the grain boundary $(\sim 1 \mu \mathrm{m})$, which is significantly smaller size than the intragranular high-Zr precipitates observed in the other studied alloys. Upon further magnification of the $\mathrm{Zr}$-rich precipitate depletion zone, Fig $3 \mathrm{~d}$ reveals submicron precipitation $\mathrm{L}_{2}{ }_{1}-\mathrm{Ni}_{2} \mathrm{TiAl}$-type precipitates inside the grains, identified based on their low- $Z$ contrast and TEM investigation, as discussed in a subsequent section.

The microstructure observed by SEM of a specimen of FBB8-6Ti which was aged at $700^{\circ} \mathrm{C}$ for $100 \mathrm{~h}$ and subsequently crept at multiple stresses at $700^{\circ} \mathrm{C}$ for $610 \mathrm{~h}$ while accumulating 7\% strain is shown in Fig 4a. Similar to the FBB8-2Ti specimen (Fig. 2), the microstructure displays large grains on the millimeter length scale. Also similar is the $\mathrm{Zr}$-rich precipitate population present within the grains and at the grain boundaries, which can be observed in Fig 4b. A uniform, precipitation-free zone, however, is not observed. At the grain boundaries, two distinct Zr-rich phases (similar to the two phases found in the FBB8-2Ti alloy) are observed, as illustrated in Fig 4c. These two phases are identified using the same labeling system introduced in Fig. 2d. Sub-micron dark Z-contrast precipitates are present within the grains, and are identified as $\mathrm{L}_{1}-\mathrm{Ni}_{2} \mathrm{TiAl}$-type precipitates with Fe-inclusions based on the TEM examination, as discussed in a later section. Upon further magnification, Fig 4d shows, along with the two Zr-rich phases present along the grain boundary, that the sub-micron size precipitates $(\mathrm{P})$ with dark Zcontrast are also present at the grain boundaries, without precipitate depletion zone at the grain boundaries. 


\subsection{TEM Investigation of Crept Microstructure}

The microstructure, and in particular the precipitate structure within the grains of the alloys, is investigated using electron diffraction and dark-field imaging and STEM. Zone axis electron diffraction patterns and superlattice dark-field images taken in [101] zone axis orientation of the FBB8-2Ti, -4Ti and 6Ti alloys in the asaged condition are contrasted in Figure 5. The precipitate structure of the Ti-free FBB8 alloy has been thoroughly investigated in previous studies [21,24] revealing a mostly B2 NiAl primary precipitate structure containing Fe-rich plates that are solid-solution-strengthened by $\mathrm{Ni}$ and $\mathrm{Al}$. The primary B2 precipitates are coherent with the $\alpha$-Fe-Ni-Cr-Al-Mo matrix.

The electron diffraction patterns in the left column of Figure 5 clearly reveal the presence of fundamental reflections, superlattice reflections corresponding to both B2-ordered and L21-ordered phases (020 and 222) and reflections that are unique to L2 ${ }_{1}$-ordered $\mathrm{Ni}_{2} \mathrm{TiAl}$ (111 and 131). The overview microstructure of the alloys is displayed in the right column of Figure 5. The 111-superlattice dark-field image of the FBB8-2Ti alloy (Figure 5b) shows a cuboidal precipitate shape with diameters ranging from 50 to $100 \mathrm{~nm}$. The dark contrast lines within the precipitates indicate the presence of a second phase creating a hierarchical $\mathrm{NiAl} /$ Ni2TiAl precipitation-strengthened ferritic alloys (denoted as HPSFA in previous publication [15]. The ADF-STEM image of the FBB8-4Ti alloy in Figure 5d shows single L2 ${ }_{1}$-ordered precipitates (denoted as SPSFA in previous publication [15]) with a spherical to ellipsoidal shape with diameters/axis between 200 to $500 \mathrm{~nm}$. A dense misfit dislocation network is observed at the matrix-precipitate interface, indicating the semi-coherent nature of the interface. The 111-superlattice dark-field image of FBB8-6Ti (Figure 5f) reveals facetted spheroidal precipitates with diameters ranging from 100 to $300 \mathrm{~nm}$. The precipitates are also semi-coherent with the bcc-Fe matrix, as indicated by the presence of a misfit dislocation network at the matrix-precipitate interface. Regions with dark contrast are also visible within the precipitates, indicating the location of a second phase within the primary precipitate. To obtain a more comprehensive understanding of the internal precipitate structure, dark-field images taken with a reflection unique to the $\mathrm{L} 2 \mathrm{2}_{1}$ phase ([111]) are contrasted with images taken with a reflection that is common to both B2 and L2 ([222]) in Fig. 6 for FBB8-2Ti, -4Ti and 6Ti alloys in the as-aged condition.

For FBB8-2Ti, a comparison of Figure $6 \mathrm{a}$ and $\mathrm{b}$ confirms the two-phase nature of the precipitates. Figure 6a shows the location of $\mathrm{L} 2{ }_{1}-\mathrm{Ni} 2 \mathrm{TiAl}$. Regions with no contrast in the same image reveal the location of $\mathrm{B} 2-\mathrm{NiAl}$ within the precipitate. The matrix-precipitate and B2-L2 1 interfaces are observed to be coherent with an interfacial alignment towards a cube-on-cube orientation. The B2-NiAl sub- 
precipitate structure exhibits plate-shape geometry with a width of $10-20 \mathrm{~nm}$, similar to that observed in [16]. For FBB8-4Ti, the superlattice dark-field images confirm that the precipitate is $\mathrm{L} 2{ }_{1}$-ordered, because of the similar contrast. The dark vertical lines within the precipitate are $1 / 2[100]$ antiphase domain boundaries, which may be originating from an order-disorder reaction or coalescing precipitates. The dark ellipsoidal regions in the center of the precipitate give the location of Fe-rich plates as observed in B2-NiAl type precipitates [18]. The precipitate structure of FBB8-6Ti in the peak-aged condition is quite similar to that present in the FBB8-4Ti. The precipitates are primarily L2 ${ }_{1}$-ordered with an internal plate-shaped Fe-rich precipitate structure. It is important to note that all of the Ti-containing alloys display precipitates with a structures different from that of the B2-NiAl precipitates found in FBB8, indicating that $\mathrm{Ti}$ partitions to the precipitates and changes their nature

\subsection{Creep properties at $700^{\circ} \mathrm{C}$}

A series of compressive creep experiments were performed for increasing stresses at $700^{\circ} \mathrm{C}$ on all samples (Table 1). The tests begin with low stresses to verify the presence of threshold stresses, which is evident by the lack of a discernable secondary strain rate after the first several tens of hours of the experiments. Figure 7 displays an example of a creep curve (strain vs. time) for a creep test performed on the FBB8-4Ti alloy with increasing applied stresses at $700{ }^{\circ} \mathrm{C}$. Upon initial loading, after an initial jump in strain, the strain rate decreases monotonically with time until a minimum secondary strain rate is achieved. This Class II primary creep behavior [25] was observed for all three Ticontaining alloys, but not for FBB8-0Ti, which showed an inverse, Class I primary behavior, as previously reported [21]. Upon subsequent stress increases, the primary creep strain is negligible.

Figure 8 shows the secondary strain rate as a function of applied stress at $700^{\circ} \mathrm{C}$ for all Ti-containing alloy compositions and for the Ti-free FBB8 from a previous study [21]. The open and filled data points in Figure 8 refer to samples tested under "peak-" and "over-aged" conditions, respectively. The latter term denotes that the sample was subjected to a series of compressive stresses for a significantly longer duration $(\sim 30$ days) at $700^{\circ} \mathrm{C}$ than the "peak-aged" sample ( 2-10 days). Since these samples were aged at $700^{\circ} \mathrm{C}$ for $100 \mathrm{~h}(\sim 4$ days) before creep testing, prolonged exposure to this temperature while creep testing leads to microstructural evolution of the sample, e.g., precipitate coarsening. The secondary strain rate at a given stress is taken to be the minimum, stable strain rate value held long enough at that stress for the total strain increment to become significantly (at least three times) larger than the resolution/error of the creep test. At low stresses for each composition, as marked with points with downward arrows in Figure 8, a secondary strain rate was not achieved; thus, an upper-bound strain rate is determined based on the displacement resolution of the strain measurement and the creep time. In the 
experimental range of strain rates, $1 \times 10^{-8}$ to $1 \times 10^{-4} \mathrm{~S}^{-1}$, the creep data overlap between the "peak-" and "over-aged" conditions for both FBB8-0Ti and -6Ti, whereas the FBB8-2Ti and -4Ti alloys show markedly different creep resistance between the two conditions. The slopes of linear fits of the strain-rate vs. stress data shown on double logarithmic plots in Figure 8 correspond to apparent stress exponents $\left(n_{a p p}=11-24\right)$ in the above experimental range of strain rates.

Several trends are shown in Figure 8 regarding the effect that titanium additions have on the creep properties of the alloy. First, the presence of titanium, in any quantity studied here (2, 4 and $6 \mathrm{wt} . \%)$, results in significant improvements in creep resistance over the Ti-free FBB8 alloy, demonstrating the strong effect that precipitation of the L2 $1^{-}$ $\mathrm{Ni}_{2} \mathrm{TiAl}$ phase has on the creep strength. Second, although the presence of titanium has an overall positive effect on creep properties, there is an inverse relationship between the amounts of titanium added (2, 4 and 6 wt. $\%)$ and the creep resistance of the alloy. This suggests that the resulting microstructures vary sensitively with small changes in the amount of $\mathrm{Ti}$ added and that an optimized Ti concentration exists for maximum creep resistance of this alloy. Third, there is no significant difference in creep resistance between the "peak-" and "over-aged" conditions for the FBB8-6Ti, whereas both the FBB8-2Ti and -4Ti show a significant decrease from the "peak-" to the "over-aged" conditions. The lack of deterioration in creep properties for the FBB8-6Ti alloys speaks to the stability of the alloy's precipitate structure, while the divergence between the two conditions for the FBB8-2Ti and -4Ti alloys implies coarsening of the microstructure. Finally, even with an evolving microstructure, FBB8-2Ti consistently displays the best creep resistance of the four alloys tested here, with roughly a four order of magnitude decrease in creep rate, for a given stress, over the Ti-free FBB8 alloy. This increase in creep performance demonstrates that the microstructure present in FBB8-2Ti is most effective at blocking the motion of dislocations in the alloys tested.

The apparent stress exponents of $n_{a p p}=11-24$ for the four studied alloys are much higher than the stress exponent $n=4$ that is observed in single-phase Fe-24Cr-4Al solid solution at a stress range of $40-100 \mathrm{MPa}$ at $600-650^{\circ} \mathrm{C}$ [26]. Previous creep studies of the FBB8-0Ti alloy at 600,650 and $700^{\circ} \mathrm{C}$ also showed high apparent stress exponent $\left(n_{\text {app }}=\right.$ 6-12)[21]. Anomalously high stress exponents usually imply strong interaction between the precipitates and the matrix dislocations, which is expressed by a threshold stress, below which the strain rate of the material is zero, or at least below laboratory measurement capability. The presence of a threshold stress has previously been reported in the FBB8-0Ti alloy [21]. A threshold stress, $\sigma_{t h}$, can be used within the modified Mukherjee-Bird-Dorn equation:

$$
\dot{\varepsilon}=A\left(\frac{\sigma_{a}-\sigma_{\text {th }}}{\mu}\right)^{n} \exp \left(\frac{-Q}{k_{B} T}\right)
$$


where $A$ is a constant, $\mu$ is the shear modulus of the matrix, $\sigma_{a}$ is the applied stress, $n$ is the stress exponent of the matrix and $Q$ is the creep activation energy. The threshold stress is obtained by a linear least-squared regression of $\dot{\varepsilon}^{1 / n}$ vs. $\sigma_{a}$ with a weight of $1 /\left(\delta^{2} \dot{\varepsilon}^{1 / n}\right)$, where $\delta^{2} \dot{\varepsilon}^{1 / n}$ is the uncertainty in the $n^{\text {th }}$ root of the strain rate [27]. The matrix stress exponent of $(n=4)$ was employed, as done successfully in previous Fe-NiAl-Cr studies [21], and provides an good linear fit in plots of $\dot{\varepsilon}^{1 / n}$ vs. applied stress for all studied compositions, as shown in Figure 8. The threshold stresses displayed in Table 2 are obtained by dividing the y-axis intercept of a linear regression analysis by its slope.

\subsection{Creep Mechanisms}

For all the above precipitation-strengthened alloys, creep resistance probably stems from matrix dislocations being impeded by elastic interaction strain fields as they bypass the precipitates. Given the large grain sizes present, diffusional creep is not expected. The vast increase in the creep strength of the FBB8-2Ti alloy (with coherent $\mathrm{L} 2{ }_{1}-\mathrm{Ni}_{2} \mathrm{TiAl}$ primary precipitates containing $\mathrm{B} 2-\mathrm{NiAl}$ plates) as compared to the Ti-free FBB8 alloy (with single-phase B2 precipitates containing Fe-rich plates) is hypothesized to result from a large change in the strength of the dislocation-precipitate interaction. Previous TEM analysis showed that the dominant creep mechanism of the Ti-free FBB8 alloy is dislocation climb bypass of B2 primary precipitates with repulsive elastic interactions due to lattice mismatch [21,28]. There are a limited number of possible mechanisms potentially active in the FBB8-2Ti alloy that can account for the very strong increase in creep resistance. First, it has been shown that the stress needed for a dislocation to bypass a precipitate via climb is greatly affected by the misfit strain field surrounding the obstacle [21]. Krug et al. showed that the magnitude of the threshold stress induced by coherent, misfitting $\mathrm{Al}_{3} \mathrm{Sc}$ precipitates dispersed within a $\mathrm{Al}$ matrix increases with increasing precipitate misfit [29]. Analogously, though the ferritic alloys studied here have a much larger precipitate volume fraction and radius, we hypothesize that for the FBB8-2Ti, the complex $\mathrm{L}_{1}-\mathrm{Ni}_{2} \mathrm{TiAl} / \mathrm{B} 2-\mathrm{NiAl}$ precipitates, display increased misfit with the matrix as compared to the $\mathrm{B} 2$ precipitates present in the Ti-free FBB8 alloy, resulting in a strain field that more effectively traps dislocations on the arrival or departure side of the precipitates. As more titanium is added to the alloy, the misfit between the precipitate and the matrix is expected to increase until eventually coherency is lost. The FBB8-4Ti and -6Ti steels indeed show $\mathrm{L}_{2}{ }_{1}-\mathrm{Ni}_{2} \mathrm{TiAl} / \mathrm{Fe}$-rich precipitates that are semi-coherent with the matrix, based on the network of dislocations present at the matrix-precipitate interface as observed via TEM and are expected to show lower misfit strains, thus explaining their lower creep resistance as compared to the FBB8-2Ti alloy. Along with the lower misfit strain, the smaller L2 1 precipitates in the FBB8-6Ti alloy (100-300 nm) induce a weaker elastic interaction with dislocations than the larger L2 1 precipitates in the FBB8-4Ti (200-500nm), which may account for the decrease in creep resistance between the alloys. 
Alternatively, it is possible that the dislocations are shearing the precipitates rather than bypassing them by climb. In this case, the increased resistance to shear of the $\mathrm{L} 21_{1}$ phase as compared to the B2 phase accounts for the favorable creep properties observed for all Ti-containing alloys [12,30]. In addition, the hierarchical nature of the precipitates in the Ti-containing alloys may force the dislocations to switch between preferred glide planes as they shear through the two-phase precipitates, thus further impeding their motion. Consequently, FBB8-2Ti demonstrates the largest creep strength because it displays plate-like $\mathrm{B} 2$ precipitates embedded in the $\mathrm{L}_{2}-\mathrm{Ni}_{2} \mathrm{TiAl}$ main precipitates; these $\mathrm{B} 2$ sub-precipitates are more creep resistant than the Fe-rich subprecipitates within the $\mathrm{L} 2_{1}-\mathrm{Ni}_{2} \mathrm{TiAl}$ precipitates displayed by both the FBB8-4Ti and -6Ti alloys. High temperature creep observations of a NiAl-Ni $\mathrm{NiAl}_{2}$ alloy by Polvani et al. [30] confirmed that a significant increase in creep strength is observed by a two phase B2/L2 $1_{1}$ alloy that is mainly attributed to the reduced motion of antiphase boundary coupled superdislocations in $\mathrm{Ni}_{2} \mathrm{TiAl}$ and dislocation networks at the $\mathrm{B} 2 / \mathrm{L} 2{ }_{1}$ interface [[12,30]]. The difference in creep resistance between FBB8-4Ti and -6Ti alloys may also be affected by the volume fractions of the $\mathrm{L}_{1}$ and Fe-rich precipitates. However, from the TEM images discussed in Section 3.2, the two alloys appear to have a similar ratio of Fe-rich phase to $\mathrm{L} 2{ }_{1}$ phases. Then, the relatively large difference in creep properties between the alloys suggests that shearing is not the dominant bypass mechanism.

In either strengthening mechanism (climb bypass or shearing), a significant difference in the total precipitate volume fraction between the studied alloys would also have significant effect on the creep behavior; however overall volume fraction was not rigorously measured in this study. To determine a definitive creep mechanism, TEM images of interrupted creep tests should be taken for each alloy composition to capture the overall precipitate volume fraction as well as the dislocation-precipitate interaction.

\section{Conclusions}

This study examines the microstructure of precipitation-strengthened ferritic alloys ( $\mathrm{Fe}-$ 10.0-10.7Cr-9.9-10.5Ni-5.4-5.8Al-3.1-3.5Mo-0.18-0.31Zr-<0.001-0.005B wt.\%), with 0, 2, 4 and 6 wt.\% Ti additions (labelled FBB8, FBB8-2Ti, FBB8-4Ti and FBB8-6Ti, respectively), and their creep properties at $700^{\circ} \mathrm{C}$ in the stress range $70-300 \mathrm{MPa}$. The following conclusions were drawn:

- SEM micrographs show grain sizes spanning a range from 0.1 to a few millimeters as well as the presence of micron-size Zr-rich precipitates along grain boundaries and within the grains for all studied alloy compositions.

- TEM micrographs reveal, in both FBB8-4Ti and -6Ti, the presence of semicoherent ellipsoidal $\mathrm{L}_{1}$-Ni2 $\mathrm{TiAl}$ precipitates (several hundreds of nanometers in diameter) containing Fe-rich plates roughly spanning the width of the precipitates. By contrast, the FBB8-2Ti exhibits cuboidal, 
coherent $\mathrm{L}_{1}-\mathrm{Ni}_{2} \mathrm{TiAl}$ precipitates $(50-100 \mathrm{~nm}$ in size) containing plate-like B2-NiAl second phases. These Ti-containing precipitates are different from the B2-NiAl ones present in FBB8, indicating that $\mathrm{Ti}$ partitions to the precipitates and change their nature.

- The Ti-containing alloys show a 1-4 order of magnitude decrease in secondary creep rate, at a given stress, over the titanium-free FBB8 composition. A creep threshold stress is observed for all alloys, with values ranging from 69 to $175 \mathrm{MPa}$ for the studied FBB8-Ti family of alloys.

- FBB8-0Ti and FBB8-6Ti display unchanged creep properties over operating times as long as $770 \mathrm{~h}$ at $700^{\circ} \mathrm{C}$, which demonstrates the stability and coarsening resistance of their precipitate structure, while the creep resistance of FBB8-2Ti and FBB8-4Ti decreases with prolonged exposure of up to $445 \mathrm{~h}$.

- Even with a coarsened microstructure, FBB8-2Ti shows creep resistance that is better than, or on par with, any of the other three alloys in their peak-aged state. FBB8-2Ti, thus, represents the most promising composition for hightemperature applications and further optimizations.

- From analysis of SEM, TEM and creep results, the threshold stresses observed for all studied alloys is hypothesized to be the result of a repulsive elastic interaction when matrix dislocations climb over (i) coherent B2-NiAl precipitate with Fe-rich inclusions for FBB8-0Ti, (ii) coherent L2 ${ }_{1}$-structured $\mathrm{Ni}_{2} \mathrm{TiAl}$ precipitates containing B2-NiAl second phases for FBB8-2Ti, or (iii) semi-coherent $\mathrm{L}_{1}-\mathrm{Ni}_{2} \mathrm{TiAl}$ precipitates containing Fe-rich plates for FBB84Ti and -6Ti. The strong sensitivity in creep resistance to Ti content is hypothesized to reflect the changes in the lattice mismatch between matrix and precipitates in this series of alloys.

Acknowledgements - This research was supported financially by the US Department of Energy (DOE), Office of Fossil Energy, under Grant DEFE0005868 (Dr. V. Cedro, monitor). The authors gratefully acknowledge Prof. P.K. Liaw, Mr. Z. Sun and Mr. G. Song (University of Tennessee) for providing the alloy and performing aging treatments. We also thank these authors and Dr. Gautam Ghosh (Northwestern University) for numerous helpful discussions. The microscopy work was performed at the National Center for Electron Microscopy in the Molecular Foundry (NCEM), which is supported by the Office of Science, Office of Basic Energy Sciences of the US Department of Energy under Contract No. DE-AC02-05CH11231. 


\section{References:}

[1] H.K.D.H. Bhadeshia, Design of Ferritic Creep-resistant Steels, ISIJ Int. 41 (2001) 626-640.

[2] C. Stallybrass, A. Schneider, G. Sauthoff, The strengthening effect of (Ni,Fe)Al precipitates on the mechanical properties at high temperatures of ferritic $\mathrm{Fe}-$ Al-Ni-Cr alloys, Intermetallics. 13 (2005) 1263-1268. doi:10.1016/j.intermet.2004.07.048.

[3] C. Stallybrass, G. Sauthoff, Ferritic Fe-Al-Ni-Cr alloys with coherent precipitates for high-temperature applications, Mater. Sci. Eng. A. 387-389 (2004) 985-990. doi:10.1016/j.msea.2004.01.108.

[4] F. Masuyama, History of Power Plants and Progress in Heat Resistant Steels, ISIJ Int. 41 (2001) 612-625.

[5] Z.K. Teng, C.T. Liu, G. Ghosh, P.K. Liaw, M.E. Fine, Effects of Al on the microstructure and ductility of NiAl-strengthened ferritic steels at room temperature, Intermetallics. 18 (2010) 1437-1443. doi:10.1016/j.intermet.2010.03.026.

[6] Z.K. Teng, F. Zhang, M.K. Miller, C.T. Liu, S. Huang, Y.T. Chou, R.H. Tien, Y. A. Chang, P.K. Liaw, New NiAl-strengthened ferritic steels with balanced creep resistance and ductility designed by coupling thermodynamic calculations with focused experiments, Intermetallics. 29 (2012) 110-115. doi:10.1016/j.intermet.2012.05.007.

[7] Z.K. Teng, C.T. Liu, M.K. Miller, G. Ghosh, E. A. Kenik, S. Huang, P.K. Liaw, Room temperature ductility of NiAl-strengthened ferritic steels: Effects of precipitate microstructure, Mater. Sci. Eng. A. 541 (2012) 22-27. doi:10.1016/j.msea.2012.01.103.

[8] A.J. Bradley, Microscpoical Studies on Iron-Nickel-Alumimium System Part II The breakdown of the body-centered cubic lattice, J. Iron Steel Inst. (1951) 233-244.

[9] W.B. Pearson, Handbook of lattice spacing and structure of metals, Pergamon Press, Oxford, 1958.

[10] C. Sudbrack, K. Yoon, R. Noebe, D. Seidman, Temporal evolution of the nanostructure and phase compositions in a model Ni-Al-Cr alloy, Acta Mater. 54 (2006) 3199-3210. doi:10.1016/j.actamat.2006.03.015.

[11] M. Durand-Charre, The microstructure of superalloys, Gordon and Breach Science, Amsterdam, 1997.

[12] P.R. Strutt, R.S. Polvmai, J.C. Ingram, Creep behavior of the heusler type structure alloy Ni2AlTi, Metall. Trans. A. 7 (1976) 23-31.

[13] P.R. Strutt, R.S. Polvmai, B.H. Kear, Dynamic Strain Ageing in Creep of $\beta$-NiAl, Scr. Mater. 7 (1973) 949-954.

[14] J. Jung, G. Ghosh, G.B. Olson, A comparative study of precipitation behavior of Heusler phase (Ni2TiAl) from B2-TiNi in Ni-Ti-Al and Ni-Ti-Al-X (X=Hf, Pd, Pt, Zr) alloys, Acta Mater. 51 (2003) 6341-6357. doi:10.1016/j.actamat.2003.08.003.

[15] G. Song, Z. Sun, L. Li, X. Xu, M.J.S. Rawlings, C.H. Liebscher, B. Clausen, J. 
Poplawsky, D.N. Leonard, S. Huang, Z. Teng, C.T. Liu, M.D. Asta, Y. Gao, D.C. Dunand, G. Ghosh, M. Chen, M.E. Fine, P.K. Liaw, Ferritic Alloys with Extreme Creep Resistance via Coherent Hierarchical Precipitates., Sci. Rep. 5 (2015) 16327. doi:10.1038/srep16327.

[16] C.H. Liebscher, V. Radmilovic, U. Dahmen, N.Q. Vo, D.C. Dunand, M. Asta, G. Ghosh, A hierarchical microstructure due to chemical ordering in the bcc lattice: Early stages of formation in a ferritic $\mathrm{Fe}-\mathrm{Al}-\mathrm{Cr}-\mathrm{Ni}-\mathrm{Ti}$ alloy, Acta Mater. 92 (2015) 220-232.

[17] Z.K. Teng, G. Ghosh, M.K. Miller, S. Huang, B. Clausen, D.W. Brown, P.K. Liaw, Neutron-diffraction study and modeling of the lattice parameters of a NiAlprecipitate-strengthened Fe-based alloy, Acta Mater. 60 (2012) 5362-5369. doi:10.1016/j.actamat.2012.05.033.

[18] Z.K. Teng, M.K. Miller, G. Ghosh, C.T. Liu, S. Huang, K.F. Russell, M.E. Fine, P.K. Liaw, Characterization of nanoscale NiAl-type precipitates in a ferritic steel by electron microscopy and atom probe tomography, Scr. Mater. 63 (2010) 6164. doi:10.1016/j.scriptamat.2010.03.013.

[19] S. Huang, D.W. Brown, B. Clausen, Z. Teng, Y. Gao, P.K. Liaw, In Situ NeutronDiffraction Studies on the Creep Behavior of a Ferritic Superalloy, Metall. Mater. Trans. A. 43 (2011) 1497-1508. doi:10.1007/s11661-011-0979-2.

[20] Z.K. Teng, F. Zhang, M.K. Miller, C.T. Liu, S. Huang, Y.T. Chou, R.H. Tien, Y. A. Chang, P.K. Liaw, Thermodynamic modeling and experimental validation of the Fe-Al-Ni-Cr-Mo alloy system, Mater. Lett. 71 (2012) 36-40. doi:10.1016/j.matlet.2011.11.056.

[21] N.Q. Vo, C.H. Liebscher, M.J.S. Rawlings, M. Asta, D.C. Dunand, Creep properties and microstructure of a precipitation-strengthened ferritic $\mathrm{Fe}-\mathrm{Al}-\mathrm{Ni}-\mathrm{Cr}$ alloy, Acta Mater. 71 (2014) 89-99. doi:10.1016/j.actamat.2014.02.020.

[22] Z. Sun, C.H. Liebscher, S. Huang, Z. Teng, G. Song, G. Wang, M. Asta, M. Rawlings, M.E. Fine, P.K. Liaw, New design aspects of creep-resistant NiAlstrengthened ferritic alloys, Scr. Mater. 68 (2013) 384-388. doi:10.1016/j.scriptamat.2012.10.040.

[23] S. Huang, G. Ghosh, X. Li, J. Ilavsky, Z. Teng, P.K. Liaw, Effect of Al on the NiAlType B2 Precipitates in Ferritic Superalloys, Metall. Mater. Trans. A. 43 (2012). doi:10.1007/s11661-012-1318-y.

[24] Z. Sun, G. Song, J. Ilavsky, G. Ghosh, P.K. Liaw, Nano-sized precipitate stability and its controlling factors in a NiAl- strengthened ferritic alloy, Sci. Rep. 5 (2015) 16081.

[25] S. V. Raj, I.S. Iskovitz, A.D. Freed, Unified constitutive laws of plastic deformation, Elsevier Science, Amsterdam, 1996.

[26] J.S. Tjong, S.C. and Zhang, Abnormal Creep Behavior of Ferritic Fe-24Cr-4Al Stainless Steel, Metall. Scr. 30 (1994) 1397-1402.

[27] R.A. Karnesky, Mechanical properties and microstructure of Al-Sc with rareearth element or Al203 additions, Northwestern Univesity, 2007.

[28] Y. Zhao, Q. Fang, Y. Liu, P. Wen, Y. Liu, Creep behavior as dislocation climb over NiAl nanoprecipitates in ferritic alloy: The effects of interface stresses and temperature, Int. J. Plast. (2015). doi:10.1016/j.ijplas.2015.02.006.

[29] M.E. Krug, D.N. Seidman, D.C. Dunand, Creep properties and precipitate 
evolution in Al-Li alloys microalloyed with Sc and Yb, Mater. Sci. Eng. A. 550 (2012) 300-311. doi:10.1016/j.msea.2012.04.075.

[30] R.S. Polvani, W.S. Tzeng, P.R. Strutt, High Temperature Creep in a Semicoherent NiAl-Ni2AlTi Alloy, Metall. Trans. A. 7A (1973.) 33-40. 


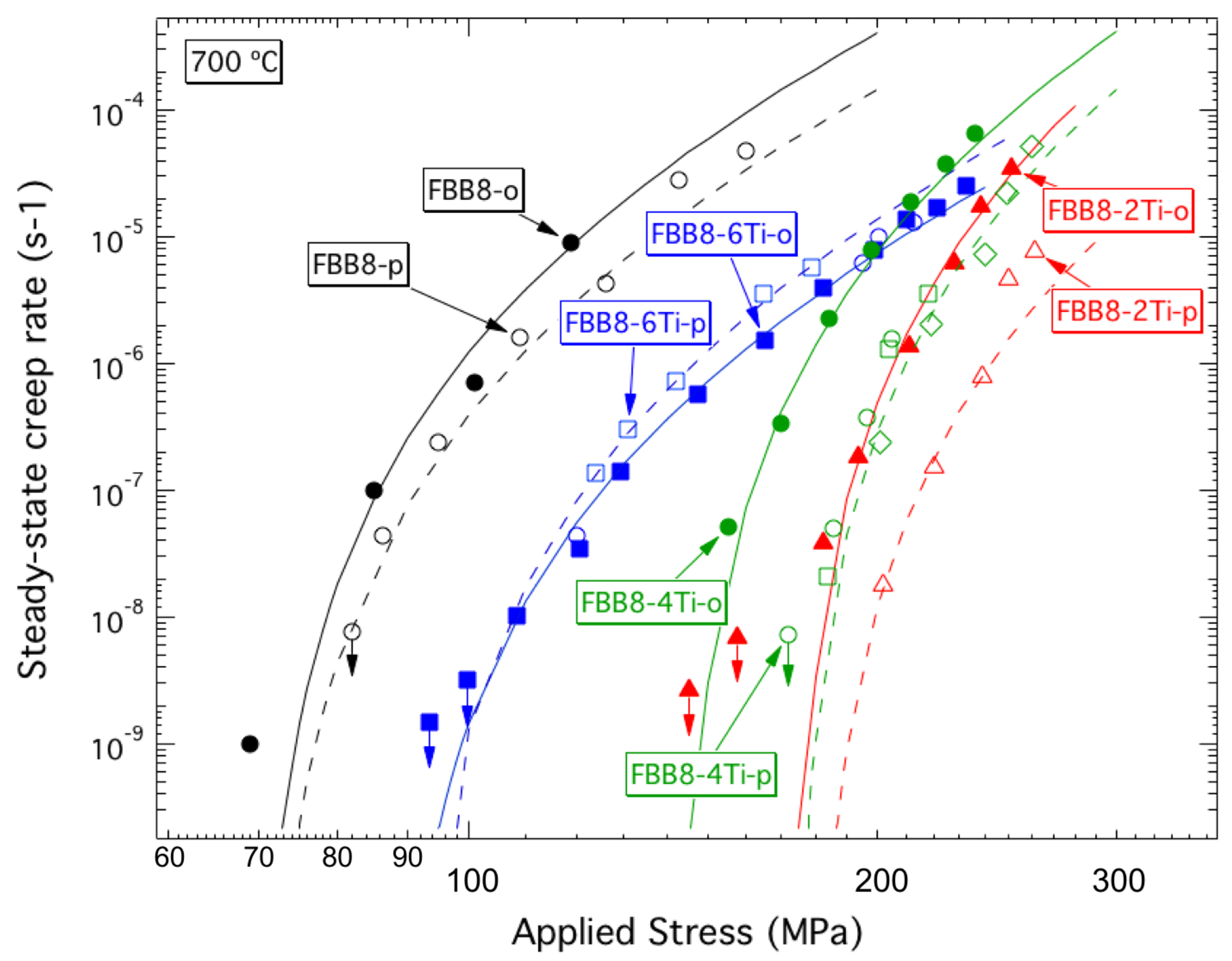



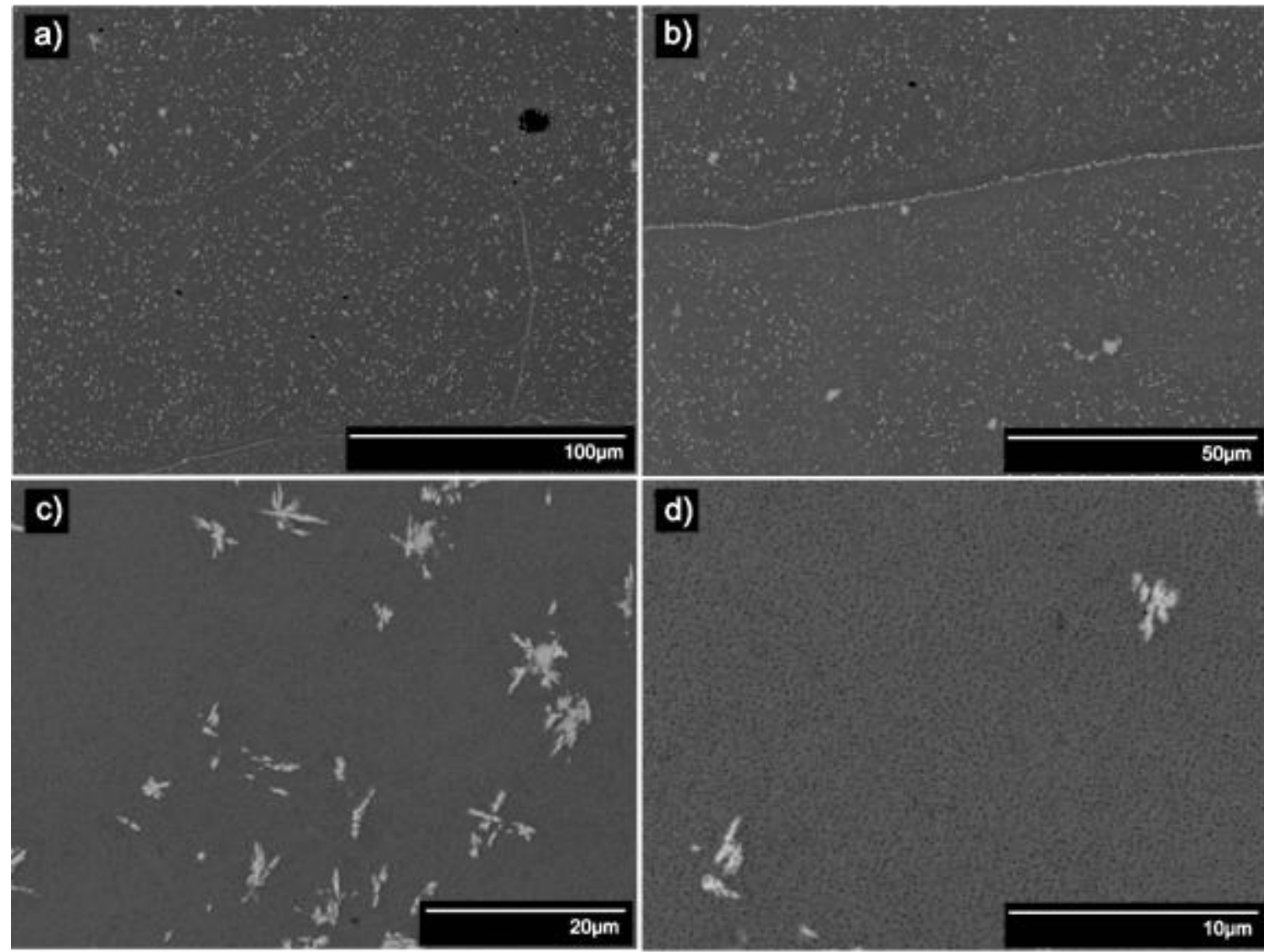

d)

Figure 1: SEM micrographs of FBB8-0Ti alloy crept at for $190 \mathrm{~h}$ at $700{ }^{\circ} \mathrm{C}$ for a range of increasing stresses (up to $165 \mathrm{MPa}$ ) at various magnifications showing (a) grains containing Zr-rich precipitates within their interior and at their boundaries (b) Zrrich precipitates at grain boundary (with precipitate-free depletion zones) and within grains grain boundary (c) and (d) intragranular Zr-rich precipitates as well as B2-NiAl precipitates with sub-micron size. 

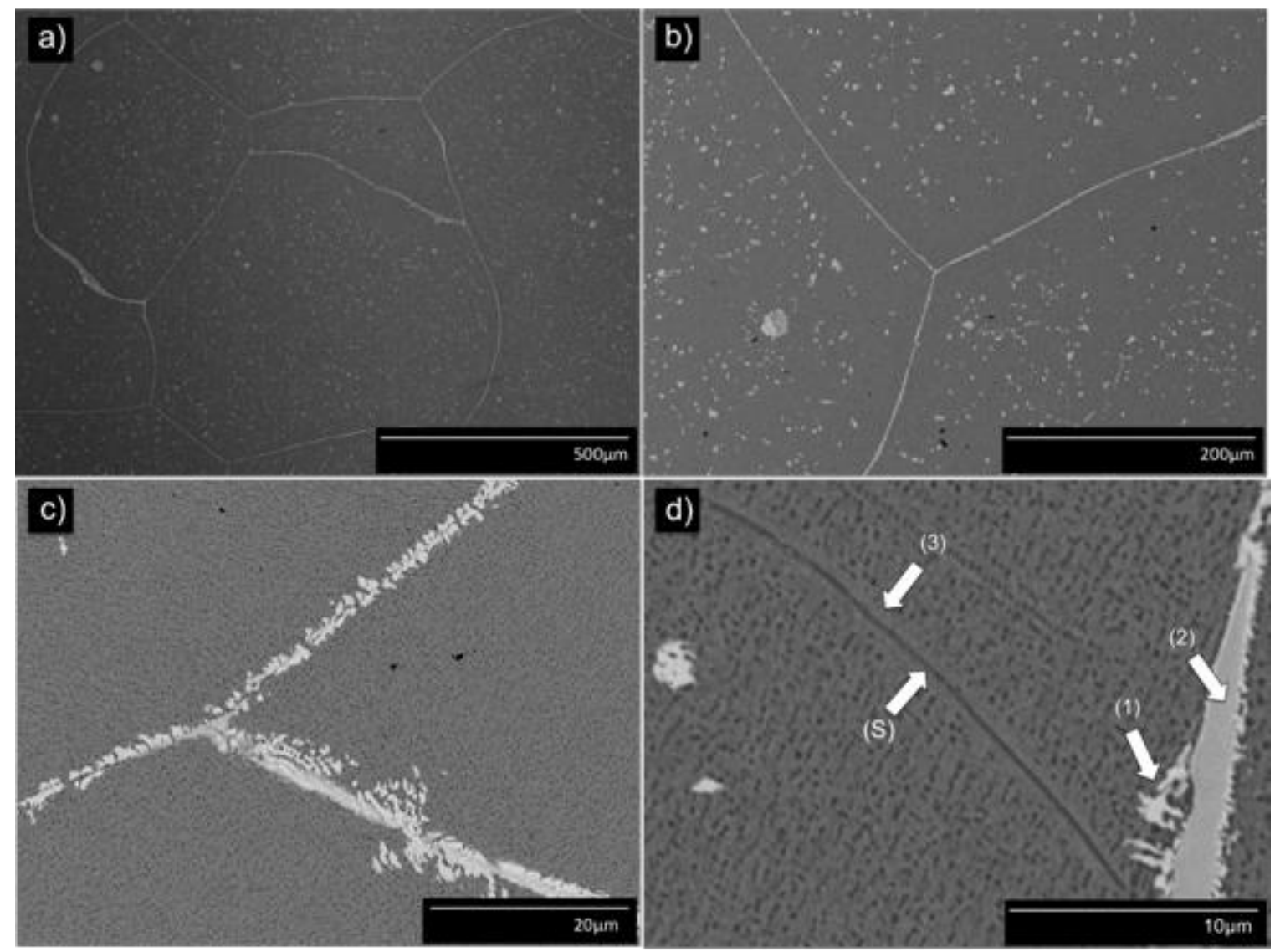

Figure 2: SEM micrographs of FBB8-2Ti alloy crept at for $410 \mathrm{~h}$ at $700{ }^{\circ} \mathrm{C}$ for a range of increasing stresses (up to $250 \mathrm{MPa}$ ) at various magnifications showing (a) grains with Zr-rich precipitates-decorated grain boundaries (b) Zr-rich precipitates at grain boundary (with precipitate-free depletion zones) and within grains (c) grain boundaries meeting at triple point, decorated with dispersion of fine Zr-rich precipitates with grains containing sub-micron size $\mathrm{L}_{2}{ }_{1}-\mathrm{Ni}_{2} \mathrm{TiAl}$ precipitates and (d) two distinct Zr-rich phases nucleated at a grain boundary (labeled 1 and 2) with uniform distribution of $\mathrm{L}_{1}-\mathrm{Ni}_{2} \mathrm{TiAl}$ precipitates within grains; $\mathrm{L}_{2}-\mathrm{Ni}_{2} \mathrm{TiAl}$ decorated sub-grain boundary (S) surrounded by a thin depletion zone (3) where no $\mathrm{L} 2_{1}$ precipitates form. 

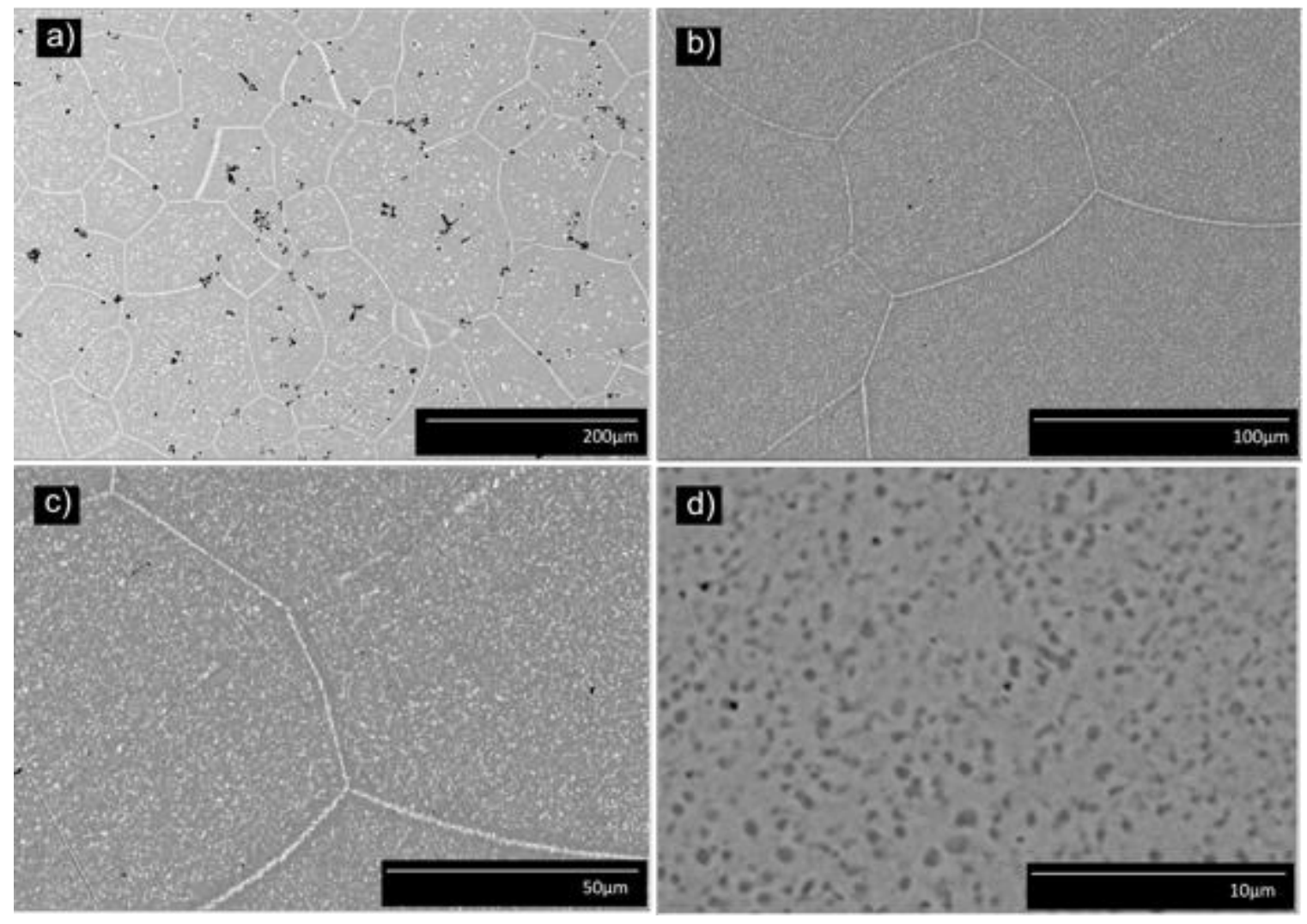

Figure 3: SEM micrographs of FBB8-4Ti crept at for $215 \mathrm{~h}$ at $700{ }^{\circ} \mathrm{C}$ for a range of increasing stresses (up to $230 \mathrm{MPa}$ ) at various magnifications showing (a) grains with sub $200 \mu \mathrm{m}$ size (black oxide particles are artefacts) (b) Zr-rich precipitates at grain boundaries and within grains (c) grain boundaries decorated with Zr-rich precipitates also present as uniform distribution within grains and (d) sub-micron size $\mathrm{L} 2{ }_{1}-\mathrm{Ni}_{2} \mathrm{TiAl}$ precipitates. 

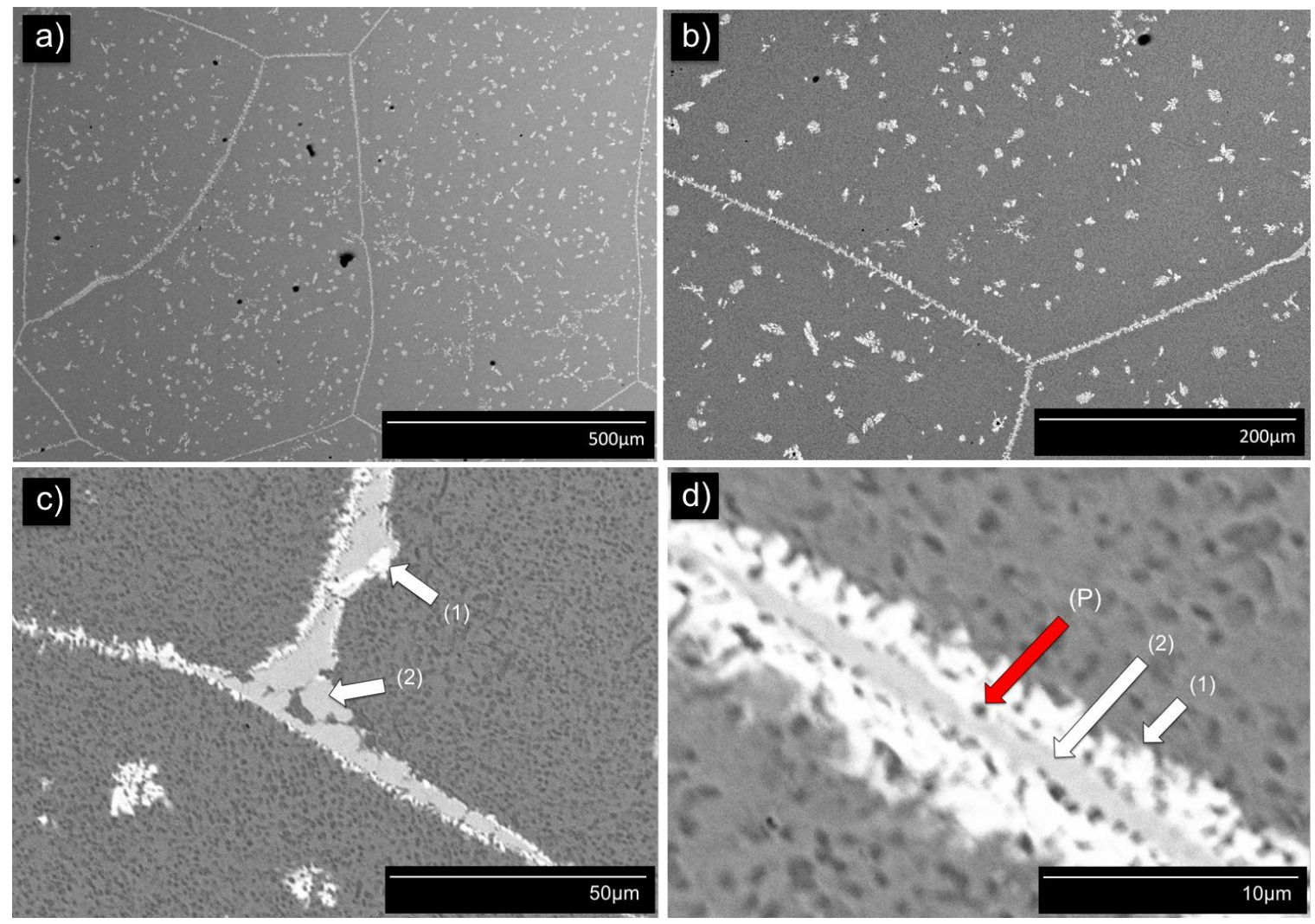

Figure 4: SEM micrographs of FBB8-6 crept at for $610 \mathrm{~h}$ at $700 \stackrel{\circ}{\mathrm{C}}$ for a range of increasing stresses (up to $200 \mathrm{MPa}$ ) at various magnifications showing (a,b) Zr-rich precipitates at grain boundary and within grains (c) two distinct $\mathrm{Zr}$-rich phases nucleated at a grain boundary (labeled 1 and 2) and sub-micron $\mathrm{L}_{2}-\mathrm{Ni}_{2} \mathrm{TiAl}$ precipitates within grains (d) grain boundary showing structure of the two $\mathrm{Zr}$-rich phases (labeled 1 and 2) containing sub-micron $\mathrm{L}_{1}{ }_{1}-\mathrm{Ni}_{2} \mathrm{TiAl}$ precipitates (P). 

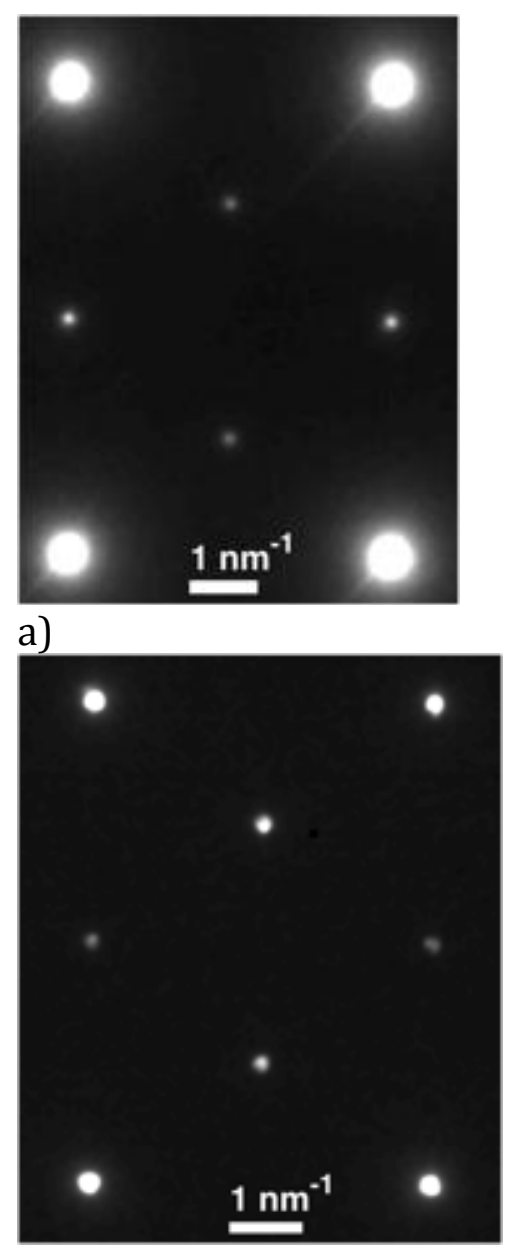

c)

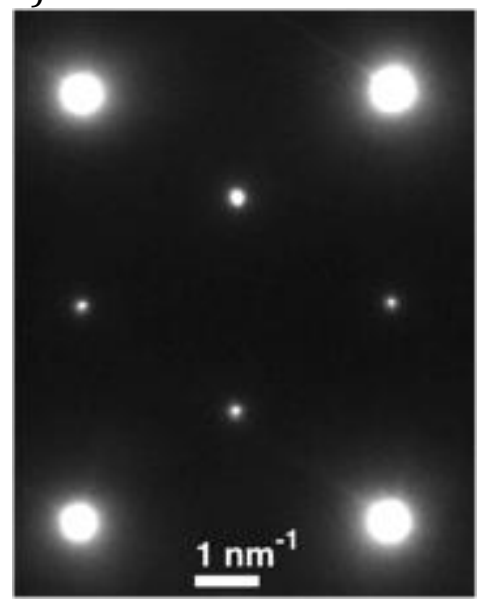

e)

Figure 5: [101] zone axis diffraction patterns and dark-field images of Ti-containing alloys in the as-aged condition. (a), (c) and (e) demonstrate a sector of the [101] electron diffraction pattern for FBB8-2Ti, $-4 \mathrm{Ti}$ and $-6 \mathrm{Ti}$ respectively. (b) and (f) are

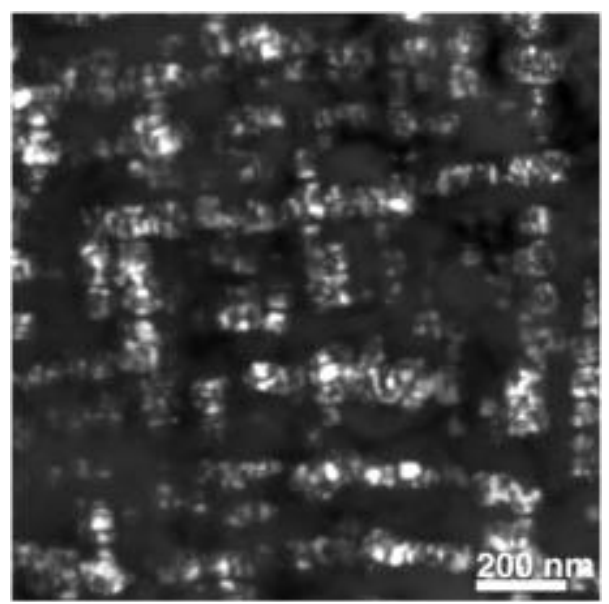

b)

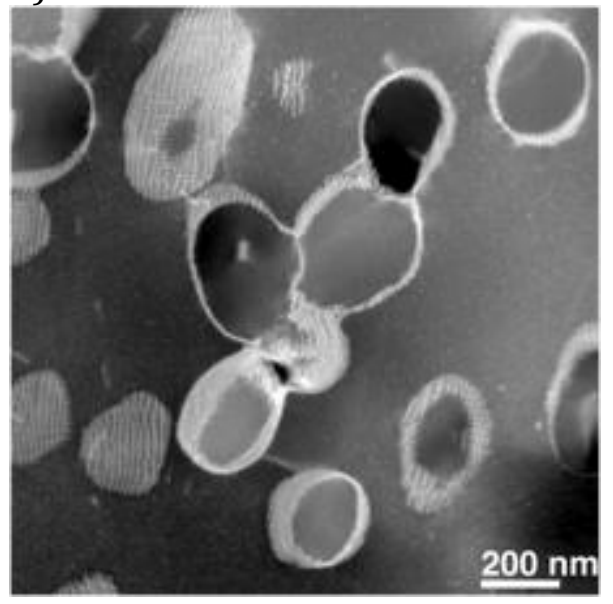

d)

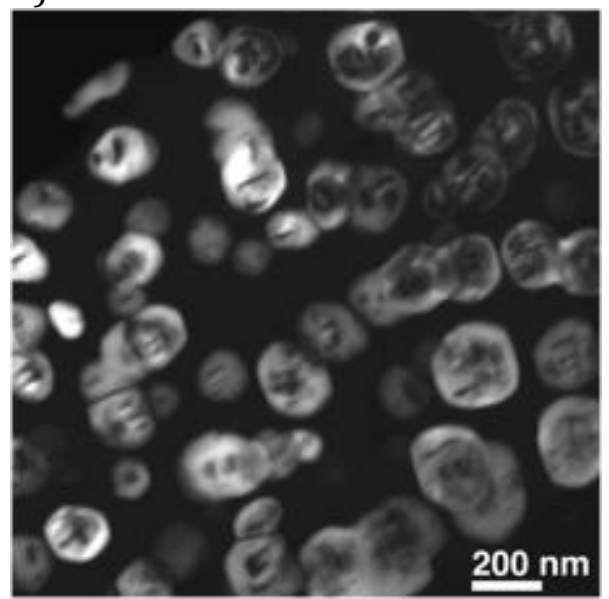

f) 
dark-field images using a 111-L21 superlattice reflection for FBB8-2Ti and -6Ti, respectively. d) shows an ADF-STEM image of FBB8-4Ti. 


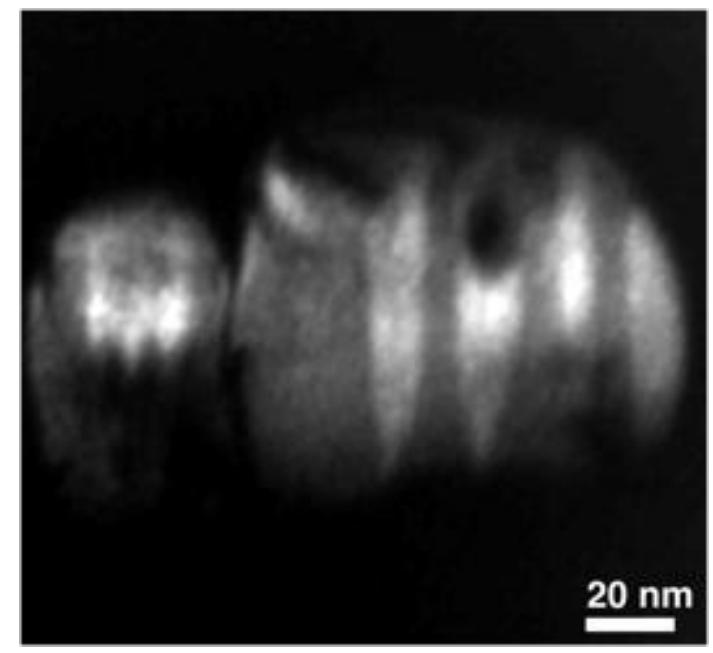

b)

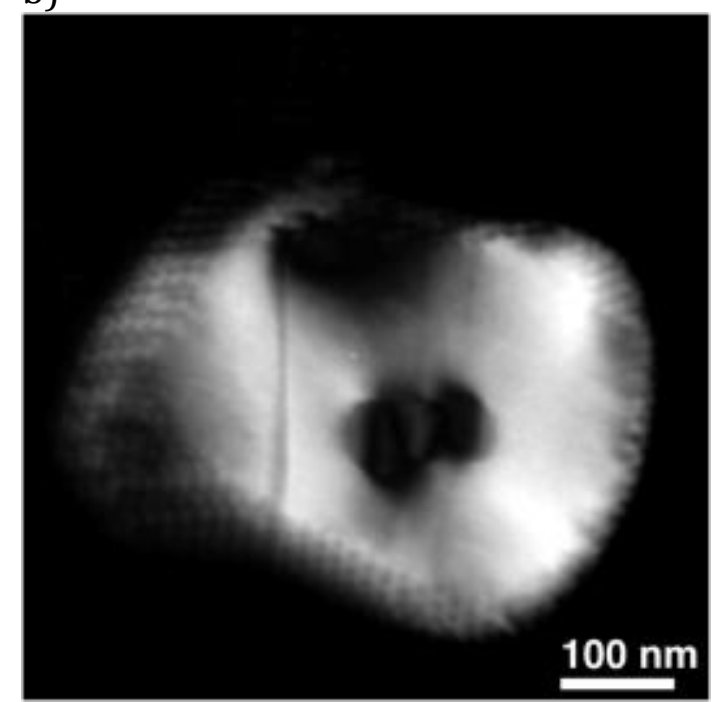

d)

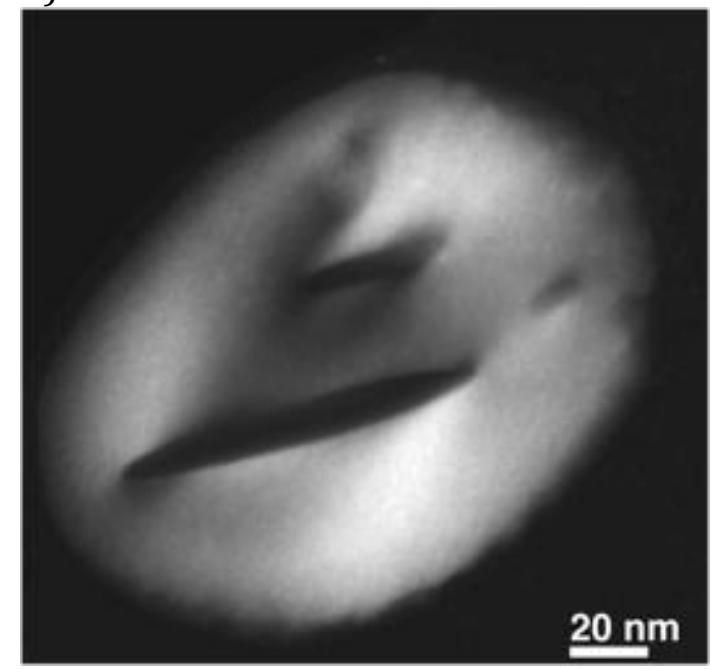

f)

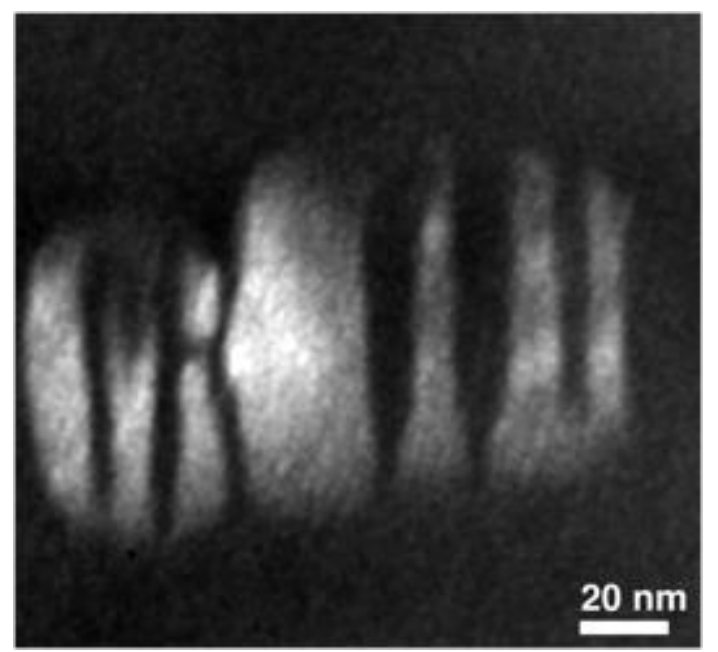

a)

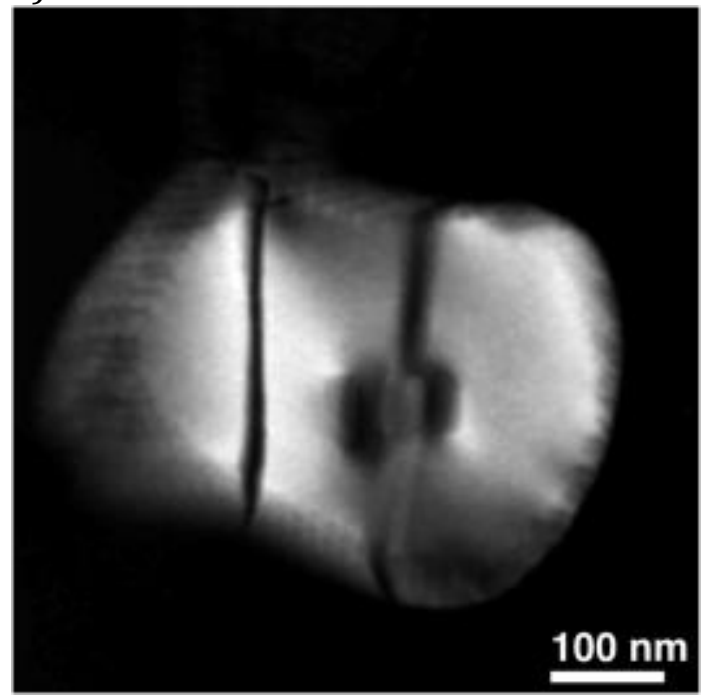

c)

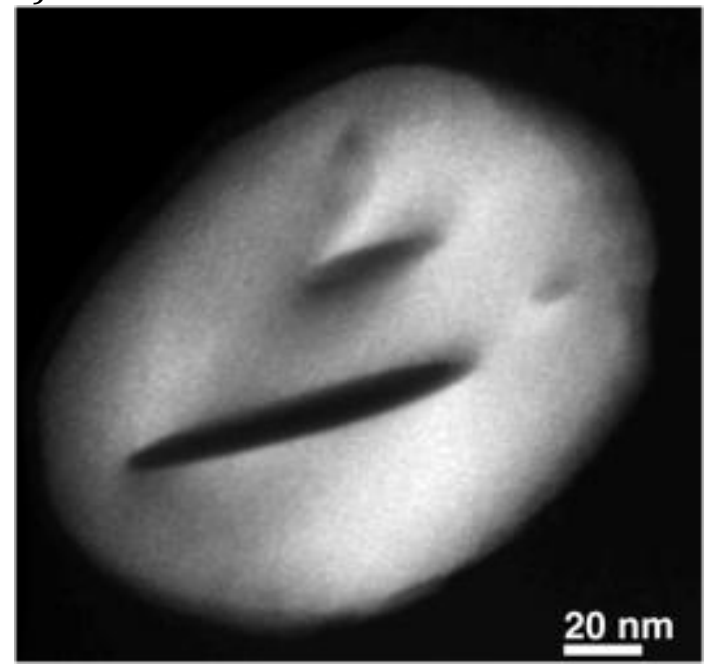

e) 
Figure 6: [101] zone axis superlattice dark-field images of (a,b) FBB8-2Ti, (c,d) FBB8-4Ti and (e,f) FBB8-6Ti in the as-aged condition. The left column illustrates images taken with an $111_{\mathrm{L} 21}$-reflection that is unique to the $\mathrm{L} 2{ }_{1}$-phase, the right column images from the same sample region imaged with a $111_{\mathrm{B} 2} / 222_{\mathrm{L} 21}$-reflection that is common to $\mathrm{B} 2$ and $\mathrm{L} 2{ }_{1}$. 


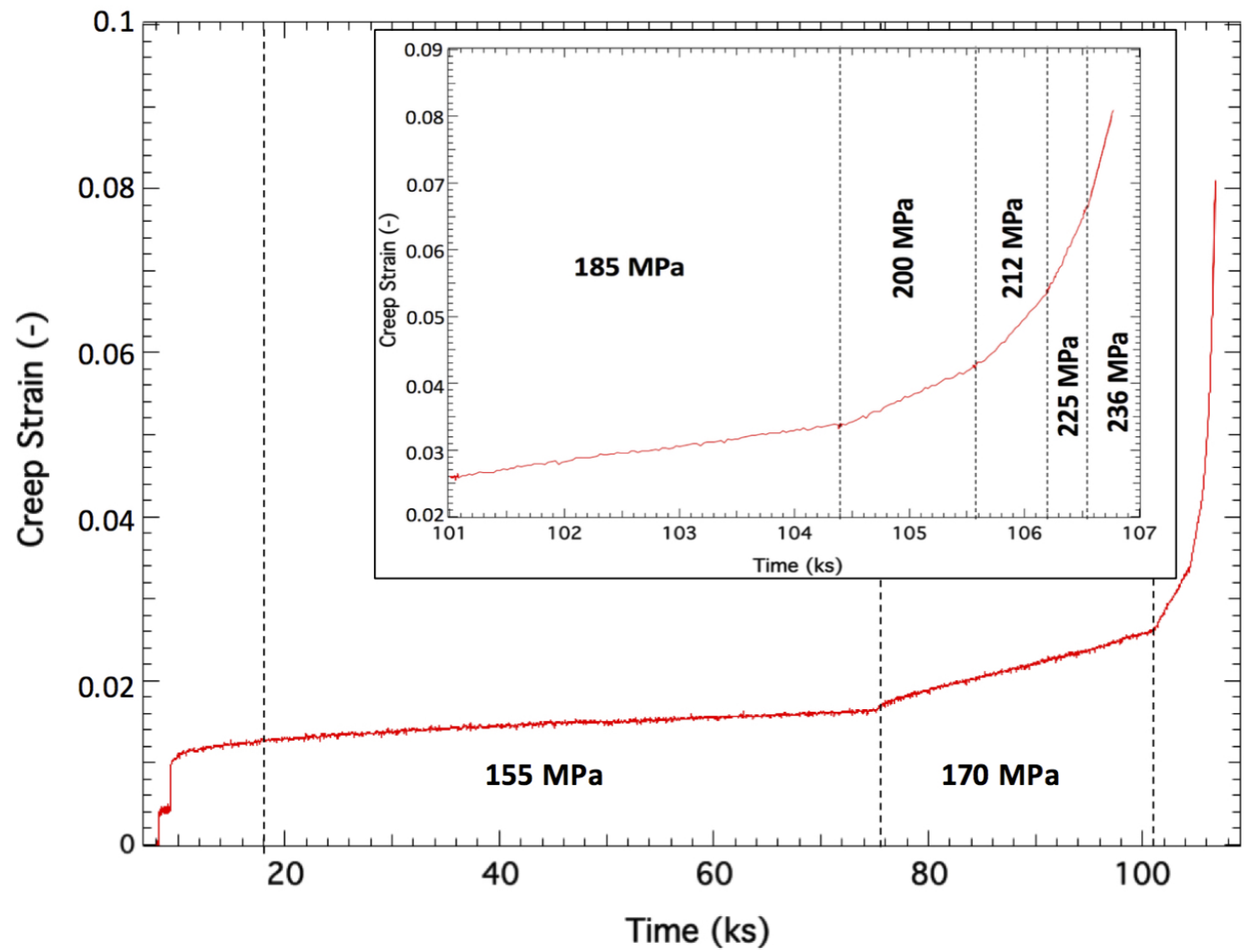

Figure 7: Plot of strain vs. time for a compression creep test performed at $700^{\circ} \mathrm{C}$ for $\sim 30 \mathrm{~h}(\sim 107 \mathrm{ks})$ on a FBB8-4Ti peak-aged sample under increasing applied stresses. The creep region before $18 \mathrm{ks}$ corresponds to elastic loading and a stepwise increase of stress before the first measurement of secondary strain rate at a stress of $155 \mathrm{MPa}$ (between 18 and $74 \mathrm{ks}$ ). 


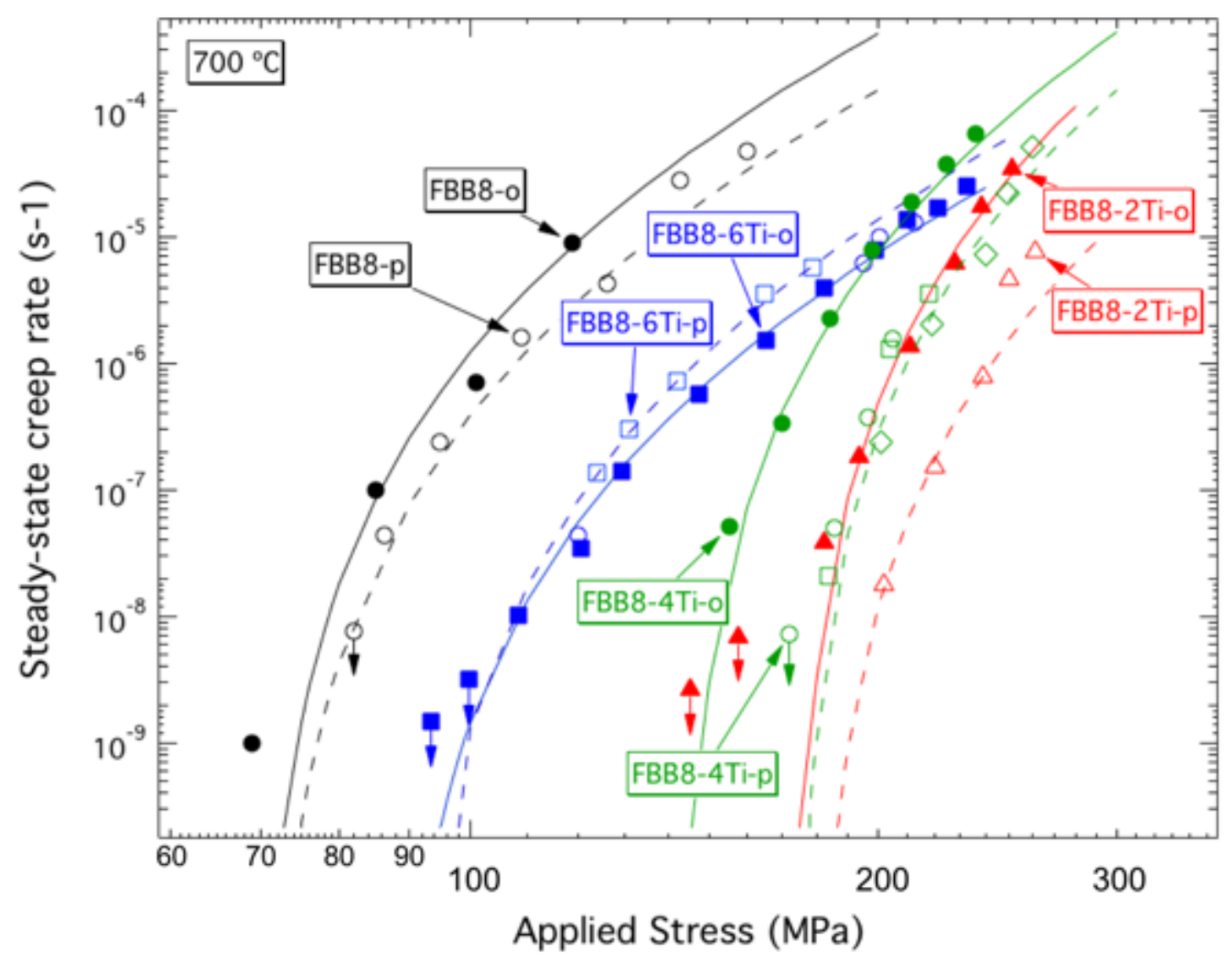

Figure 8: Double logarithmic plot of applied stress vs. steady-state strain rate of compression creep tests preformed at $700^{\circ} \mathrm{C}$ for FBB8-0\%Ti (black), FBB8-2\%Ti (red), FBB8-4\%Ti (green) and FBB8-6\%Ti alloys (blue). Data for FBB8 alloy was obtained from Ref. [15]. Different symbols represent tests repeated on different samples for reproducibility while over-aged (closed) and peak-aged (open) symbols correlate to the amount of time the sample was exposed to the operating temperature (see text). Data with downward arrow indicates upper bound values (discernable creep rate not achieved). Eq. (1) was used to fit (dash lines) the experimental data (see text). 
Table 1: Nominal (first line) and measured (subsequent lines) compositions of the FBB8+Ti alloys in wt.\%.

\begin{tabular}{lllllllll}
\hline Alloy & Fe & Al & Cr & Ni & Ti & Mo & Zr & B \\
\hline Nominal & Bal. & 6.5 & 10 & 10 & $0,2,4,6$ & 3.4 & 0.25 & 0.005 \\
FBB8 & Bal. & 5.5 & 10.4 & 10.2 & 0 & 3.4 & 0.31 & $<0.001$ \\
FBB8-2Ti & Bal. & 5.8 & 10.4 & 9.9 & 2.0 & 3.1 & 0.26 & $<0.001$ \\
FBB8-4Ti & Bal. & 5.4 & 10.0 & 10.4 & 3.8 & 3.5 & 0.18 & 0.005 \\
FBB8-6Ti & Bal. & 5.7 & 10.7 & 10.5 & 5.8 & 3.2 & 0.26 & $<0.001$ \\
\hline
\end{tabular}


Table 2: Creep threshold stresses for the FBB8+Ti alloys.

\begin{tabular}{ccc}
\hline Alloy & Aging & Threshold Stress (MPa) \\
\hline FBB8 & Peak-aged & $69[21]$ \\
& Over-aged & $70[21]$ \\
FBB8-2Ti & Over-aged & 172 \\
& PBB8-4Ti & 179 \\
& Oveak-aged & 143 \\
FBB8-6Ti & Peak-aged & 170 \\
& Over-aged & 87 \\
\hline
\end{tabular}

